\title{
Commentary: Should lung cancer screening guidelines go up in smoke?
}

\author{
Natalie S. Lui, MD, MAS
}

\author{
From the Division of Thoracic Surgery, Department of Cardiothoracic Surgery, Stanford University, Stanford, \\ Calif. \\ Disclosures: Author has nothing to disclose with regard to commercial support. \\ Received for publication May 13, 2019; accepted for publication May 14, 2019; available ahead of print June 27, \\ 2019. \\ Address for reprints: Natalie S. Lui, MD, MAS, 300 Pasteur Dr, Falk Building, Stanford, CA 94305 (E-mail \\ natalielui@stanford.edu). \\ J Thorac Cardiovasc Surg 2019;158:1257-8 \\ $0022-5223 / \$ 36.00$ \\ Copyright (C) 2019 by The American Association for Thoracic Surgery \\ https://doi.org/10.1016/j.jtcvs.2019.05.039
}

In this issue of the Journal, Bravo-Iñiguez and colleagues ${ }^{1}$ use 2 previously developed lung cancer risk models to show that non-smoking-related risk factors significantly increase the probability of development of lung cancer. The Liverpool Lung Project (LLP) ${ }^{2}$ and the Prostate, Lung, Colorectal, and Ovarian Cancer Screening Trial (PLCO) ${ }^{3}$ models estimate the risk of development of lung cancer on the basis of smoking history and non-smoking-related risk factors, such as family history of lung cancer and asbestos exposure. According to these models, a never smoker with several non-smoking-related risk factors has a higher risk of lung cancer than does a heavy smoker with no other risk factors.

These findings are important to note, because our current lung cancer screening guidelines ${ }^{4}$ and coverage ${ }^{5}$ are based on age and smoking history alone and do not take into account any other risk factors. The National Lung Screening Trial participants were between 55 and 74 years of age, had a smoking history of at least 30 pack-years, and either were current smokers or had quit within 15 years. ${ }^{6}$ Several subsequent lung cancer screening trials in Europe also enrolled participants on the basis of age and smoking history alone. ${ }^{7-12}$ The National Comprehensive Cancer Network ${ }^{13}$ and the American Association for Thoracic Surgery ${ }^{14}$ guidelines include non-smoking-related risk factors, but they recommend screening only for patients who also have a smoking history.

As the LLP and PLCO risk models show, however, although smoking is the greatest risk factor by far, there are several other important risk factors that can lead to a cumulative increase in risk. In fact, the incidence of lung cancer in never smokers has been growing steadily. In Asia, the proportion of patients with lung cancer who are never smokers is much higher than in the United States and Europe ${ }^{15}$ and several institutions have started low-dose computed tomographic screening for the general population, regardless of smoking history. ${ }^{16-18}$

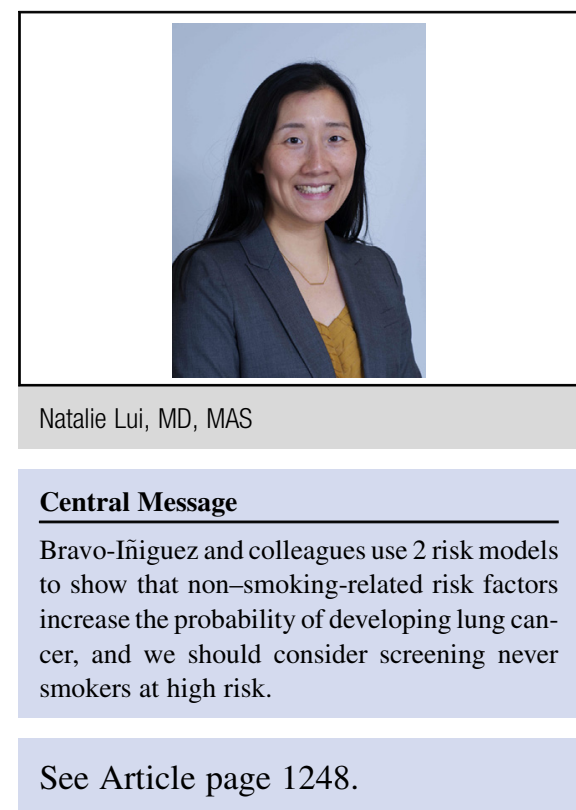

This study has several limitations related to the 2 previously developed risk models. Both LLP and PLCO risk models were based on case-control studies that relied on volunteers. They used narrow cohorts, and they thus may not be accurate in predicting the risks of lung cancer in other populations. Approximately $99 \%$ of the LLP participants were white, ${ }^{2}$ and most of the PCLO participants had a high socioeconomic status. ${ }^{3}$ In addition, the risk models did not include all non-smoking-related risk factors, such as secondhand smoke and radon exposure.

This study uses the LLP and PLCO risk models to demonstrate that non-smoking-related risk factors greatly increase the risk of development of lung cancer. We should consider screening never smokers who have other significant risk factors, and we should develop new lung cancer screening guidelines to address these patients.

\section{References}

1. Bravo-Iñiguez CE, Fox SW, De Leon LE, Tarascio JN, Jaklitsch MT, Jacobson FL. Cumulative nonsmoking risk factors increase the probability of developing lung cancer. J Thorac Cardiovasc Surg. 2019;158:1248-54.e1.

2. Cassidy A, Myles JP, van Tongeren M, Page RD, Liloglou T, Duffy SW, et al. The LLP risk model: an individual risk prediction model for lung cancer. Br J Cancer. 2008;98:270-6.

3. Tammemagi CM, Pinsky PF, Caporaso NE, Kvale PA, Hocking WG, Church TR et al. Lung cancer risk prediction: Prostate, Lung, Colorectal And Ovarian Cancer Screening Trial models and validation. J Natl Cancer Inst. 2011;103: $1058-68$. 
4. Moyer VA, U.S. Preventive Services Task Force. Screening for lung cancer: U.S Preventive Services Task Force recommendation statement. Ann Intern Med. 2014;160:330-8.

5. Medicare.gov. Lung cancer screenings. Available at: https://www.medicare.gov/ coverage/lung-cancer-screenings. Accessed June 18, 2019.

6. National Lung Screening Trial Research Team, Aberle DR, Adams AM, Berg CD, Black WC, Clapp JD, Fagerstrom RM, et al. Reduced lung-cancer mortality with low-dose computed tomographic screening. N Engl J Med. 2011;365: 395-409.

7. van Iersel CA, de Koning HJ, Draisma G, Mali WP, Scholten ET, Nackaerts K, et al. Risk-based selection from the general population in a screening trial: selection criteria, recruitment and power for the Dutch-Belgian randomised lung cancer multi-slice CT screening trial (NELSON). Int J Cancer. 2007;120:868-74.

8. Field JK, Duffy SW, Baldwin DR, Whynes DK, Devaraj A, Brain KE, et al. UK Lung Cancer RCT Pilot Screening Trial: baseline findings from the screening arm provide evidence for the potential implementation of lung cancer screening. Thorax. 2016;71:161-70.

9. Pastorino U, Silva M, Sestini S, Sabia F, Boeri M, Cantarutti A, et al. Prolonged lung cancer screening reduced 10-year mortality in the MILD Trial. Ann Oncol. June 5, 2019 [Epub ahead of print].

10. Infante M, Cavuto S, Lutman FR, Passera E, Chiarenza M, Chiesa G, et al; DANTE Study Group. Long-term follow-up results of the DANTE trial, a randomized study of lung cancer screening with spiral computed tomography. Am J Respir Crit Care Med. 2015;191:1166-75.
11. Paci E, Puliti D, Lopes Pegna A, Carrozzi L, Picozzi G, Falaschi F, et al; the ITALUNG Working Group. Mortality, survival and incidence rates in the ITALUNG randomised lung cancer screening trial. Thorax. 2017;72:825-31.

12. Wille MM, Dirksen A, Ashraf H, Saghir Z, Bach KS, Brodersen J, et al. Results of the Randomized Danish Lung Cancer Screening Trial with Focus on High-Risk Profiling. Am J Respir Crit Care Med. 2016;193:542-51.

13. Wood DE, Kazerooni EA, Baum SL, Eapen GA, Ettinger DS, Hou L, et al. Lung cancer screening, version 3.2018, NCCN clinical practice guidelines in oncology. J Natl Compr Canc Netw. 2018;16:412-41.

14. Jaklitsch MT, Jacobson FL, Austin JH, Field JK, Jett JR, Keshavjee S, et al. The American Association for Thoracic Surgery guidelines for lung cancer screening using low-dose computed tomography scans for lung cancer survivors and other high-risk groups. J Thorac Cardiovasc Surg. 2012;144:33-8.

15. Subramanian J, Govindan R. Lung cancer in never smokers: a review. J Clin Oncol. 2007;25:561-70.

16. Nawa T, Nakagawa T, Mizoue T, Endo K. Low-dose computed tomography screening in Japan. J Thorac Imaging. 2015;30:108-14.

17. Wu FZ, Huang YL, Wu CC, Tang EK, Chen CS, Mar GY, et al. Assessment of selection criteria for low-dose lung screening CT among Asian ethnic groups in Taiwan: from mass screening to specific risk-based screening for nonsmoker lung cancer. Clin Lung Cancer. 2016;17:e45-56.

18. Fan L, Wang Y, Zhou Y, Li Q, Yang W, Wang S, et al. Lung cancer screening with low-dose CT: baseline screening results in Shanghai. Acad Radiol. December 14, 2018 [Epub ahead of print]. 